\title{
Serum Total Homocysteine Level in Association with Folate and Vitamin B12 Status Among Algerian Prostate Cancer Patients
}

\author{
Type of article: Conference abstract \\ Rima Mouhoub (1), Karima Haddad (1), Meriem Belhout (1), Abdel Aziz Chibane (2) , Mohamed \\ El-Hadi Cherifi (3) ,Bahia Djerdjouri (1), Malika Khelil(1). \\ (1) Department of Cellular and Molecular Biology, Faculty of Biological Sciences, USTHB. Algeria. \\ (2) Department of Urology, Medical University Hospital of Mustapha Bacha, Algiers, Algeria. \\ (3) Department of Biochemistry, Medical University Hospital of Bainem, Algiers, Algeria. \\ mouhoub.rima@gmail.com
}

\begin{abstract}
Background: Folate, vitamin B12 and homocysteine are essential for methyl group metabolism and thus also for DNA methylation and metabolic disorders may lead to carcinogenesis metabolic disorders, which may lead to carcinogenesis. In the present study, we proposed to evaluate the associations between folate and vitamin B12, with fasting plasma tHcy concentration in prostate cancer $(\mathrm{PCa})$ patients.

Methods: A case -control study was conducted with 40 newly patients with prostate cancer diagnosed and 50 age matched healthy controls. Serum level of total homocysteine, folate, and vitamin B12 were measured by enzyme conversion immunoassay and radio assay, respectively using the ARCHITECT system (both Abbott-Diagnostics Division).

Results: The average rate of total PSA was $20.97 \mathrm{ng} / \mathrm{ml}$ (ranged between $8-60 \mathrm{ng} / \mathrm{ml}$ ). 53\% of patients had a $P S A \geq 20 \mathrm{ng} / \mathrm{ml}$. Histology confirmed that all patients accounted for prostatic adenocarcinoma with prognostic Gleason score that ranged between 7 and 8 . There are no significant differences between cases and controls about serum Hcy levels (adjusted OR $=0.160 \%$ $\mathrm{CI}=0.832-1.031$ ), folate levels (adjusted $\mathrm{OR}=0.428 \% \mathrm{CI}=0.977-1.008$ ) and vitamin $\mathrm{B} 12$ (adjusted OR $=0.103 \% \mathrm{CI}=0.992-1.001$ ).

Conclusion: In this study, the results show that homocysteine is not involved in prostate cancer. However, this study shows that the sporadic form is much more prevalent than familial one. The diagnosis is often made too late in advanced stage with a high PSA levels and biopsy showing high levels of Gleason

Keywords: Prostate cancer; Homocysteine, Vitamin B12, Folate.
\end{abstract}

\section{Conflict of interest statement}

This article is an abstract selected from the International Congress on Health Sciences and Medical Technologies, Algiers, Algeria, October 21-23, 2018.

\section{Authors' biography}

No biography

\section{References}

No references 